\title{
Composição florística de trechos florestais na borda sul-amazônica.
}

\author{
Natália Macedo IVANAUSKAS ${ }^{1}$, Reinaldo MONTEIRO ${ }^{2}$, Ricardo Ribeiro RODRIGUES ${ }^{3}$
}

\begin{abstract}
RESUMO
Este estudo apresenta a composição florística de trechos de uma faixa de vegetação de transição existente na região centro-leste do Estado de Mato Grosso, mais precisamente no município de Gaúcha do Norte $\left(13^{\circ} 10^{\prime} \mathrm{S}\right.$ e $\left.53^{\circ} 15^{\prime} \mathrm{O}\right)$, onde dá-se o contato entre a Floresta Ombrófila e a Floresta Estacional. O levantamento florístico foi realizado em março de 1999 e bimestralmente a partir de agosto de 1999 até março de 2001, em excursões com duração média de 5 dias, por meio de caminhadas na borda e no interior de florestas, sendo coletadas fanerógamas em fase reprodutiva. Também foram incluídas amostras vegetativas de espécies arbustivo-arbóreas, que não floresceram ou frutificaram durante o período de amostragem, amostradas em 3 ha destinados ao levantamento fitossociológico. O levantamento florístico resultou em 72 famílias, 168 gêneros e 268 espécies. Do total de espécies, 66\% apresentaram hábito arbóreo e 18\% foram lianas. As ervas e arbustos praticamente restringiram-se às áreas de borda ou clareiras, somando 13\%. Já a flora epifítica mostrou-se pouco expressiva (1\%), quando comparada ao restante da Amazônia, em conseqüência do clima regional mais seco. Hemiepífitas, parasitas e palmeiras constituíram o percentual restante. Constatou-se que 39 espécies amostradas em Gaúcha do Norte ainda não haviam sido depositadas em herbários que mantém coleções representativas da flora matogrossense, enfatizando a carência de coletas nas áreas florestais do Estado.
\end{abstract}

\section{PALAVRAS-CHAVE}

Amazônia, floresta amazônica, flora.

\section{Floristic composition of forest patches in soutbern Amazonia.}

\begin{abstract}
This paper shows the floristic composition of forest patches in a zone of transition vegetation which exists in the central-east region of Mato Grosso state, more specifically in the municipality of Gaúcha do Norte $\left(13^{\circ} 10^{\prime} \mathrm{S}\right.$ and $53^{\circ} 15^{\prime}$ W) where it connects the tropical rain-forest and the seasonal forest. The floristic survey was performed in March 1999 and bisemesterly from August 1999 to March 2001 (during excursions of an average of five days duration) on treks through the border and inside the forests and fanerogamous flora were collected in the reproductive phase. Vegetational samples of shrub-woody species which do not flower or fruit during the sample period were also collected from the 3 ba of the phytosociological survey. The floristic survey resulted in 72 families, 168 genera and 268 species. Of the species, $66 \%$ were woody and $18 \%$ were lianas. The herbs and shrubs were practically restricted to the border areas or clearings and formed $13 \%$ of the total. The epiphytic flora was not very expressive (1\%) when compared to the rest of the Amazon forest, due to the extremely dry regional climate. Hemiepiphytas, parasites and palm trees constituted the remaining percentage. Thirty nine of the species sampled in Gaúcha do Norte had not, at that time, been deposited in the herbaria which maintain representative collections of the flora of Mato Grosso, emphasizing the need for collections in the forest areas of this state.
\end{abstract}

\section{KEY WORDS}

Amazon, Tropical Rain Forest, Floristic Composition.

\footnotetext{
${ }^{1}$ Departamento de Biologia, Instituto de Ciências Naturais e Tecnológicas, Universidade do Estado de Mato Grosso, Caixa Postal 08, 78690-000 - Nova Xavantina-MT.nivanaus@yahoo.com.br

${ }_{2}^{2}$ Departamento de Botânica, Instituto de Biociências, Universidade Estadual Paulista, 13.506-900, Rio Claro-SP. reimonte@rc.unesp.br

${ }^{3}$ Departamento de Ciências Biológicas, Escola Superior de Agricultura "Luiz de Queiroz"/Universidade de São Paulo, Caixa Postal 09, 13418-900 Piracicaba - SP. rrr@esalq.usp.br
} 


\section{ACTA \\ AMAZONICA}

COMPOSIÇÃO FLORÍSTICA DE TRECHOS FLORESTAIS

NA BORDA SUL-AMAZÔNICA

\section{INTRODUÇÃO}

As espécies nativas da flora matogrossense são pouco conhecidas, existindo grandes lacunas de coleta. Um breve histórico sobre as primeiras explorações botânicas realizadas no Mato Grosso podem ser encontradas em Sampaio (1916) e Ackerly et al. (1989). Revisões mais recentes foram realizadas a partir de 1992, quando o governo estadual implantou o plano de zoneamento do Estado (SEPLAN/MT, 1999), que teve como um dos seus objetivos mapear a cobertura vegetal de Mato Grosso, bem como a localização dos principais pontos de levantamentos florísticos e inventários florestais já realizados.

Constatou-se que existe um grau de informação razoável sobre a composição florística e a estrutura das diferentes fisionomias que compóem o cerrado matogrossense, concentradas em duas regiões principais: o Pantanal de Mato Grosso e o trecho Depressão Cuiabana - Chapada dos Guimarães. No entanto, as áreas de transição para a Floresta Ombrófila, presentes em grande extensão em toda a porção central do Estado (entre as latitudes $11^{\circ} \mathrm{S}$ e $14^{\circ} \mathrm{S}$ ), foram objeto de pouco ou nenhum estudo, merecendo atenção especial dos futuros trabalhos.

Além das publicações, outra forma de se conhecer o patrimônio florístico de uma região é através do material científico depositado em herbários. As informações contidas nestes locais constituem-se na fonte primária para o desenvolvimento de trabalhos taxonômicos, evolutivos, fenológicos, ecológicos, biogeográficos, etnobotânicos e estudos de biodiversidade (Peixoto \& Barbosa, 1998).

No entanto, a região Centro-oeste do Brasil é ainda pouco explorada por botânicos, pois apenas o Distrito Federal e os Estados de Goiás e Tocantins têm representação significativa nas coleções de herbário, somando 291.446 espécimes de fanerógamas distribuídas em 5 herbários. O Estado de Mato Grosso, com um acervo de cerca de 17.000 exemplares (Herbários UFMT e NX), é o que se encontra em pior situação frente ao restante do país, embora apresente grande número de unidades de conservação de uso direto ou indireto (Ferreira et al., 1999) e um extenso território.

Deste modo, considerando o conjunto de dados provenientes das publicações e dos materiais depositados em herbários, pode-se afirmar que a flora matogrossense ainda é pouco conhecida, principalmente nas áreas de transição entre os biomas da floresta amazônica e do Cerrado.

Infelizmente, esta mesma flora está atualmente sob forte pressão de desmatamento para fins agrícolas e madeireiros, o que pode estar destruindo imensuráveis estoques genéticos, dos quais pouco se conhece ou está conservado em herbário ou em bancos de germoplasma. Esta erosão genética pode implicar na perda de informações preciosas, inclusive para o interesse humano, como nas áreas da agricultura, na medicina e na indústria (Flint, 1991).
Frente a este panorama pouco otimista, estudos visando o conhecimento da flora regional e a incorporação do material científico coletado em herbários devem ser incentivados. Neste contexto, este trabalho tem por objetivo investigar a composição florística de uma área de transição entre a floresta ombrófila e a floresta estacional do Estado de Mato Grosso, produzindo uma lista de espécies vasculares existentes no local, e contribuindo assim para o maior conhecimento da flora matogrossense e de sua distribuição geográfica.

\section{MATERIAL E MÉTODOS}

A área de estudo localiza-se no município de Gaúcha do Norte-MT $\left(13^{\circ} 10^{\prime} \mathrm{S}\right.$ e $55^{\circ} 15^{\prime} \mathrm{O}, 390 \mathrm{~m}$ de altitude) (Figura 1), sob clima Tropical Chuvoso de Savana (Aw) segundo Köppen (1948). As coletas de material botânico foram realizadas nas áreas florestais presentes no entorno do município e, principalmente, em três localidades destinadas ao levantamento fitossociológico:

Área 1 - propriedade do Sr. Lauri Stoffel $\left(13^{\circ} 12^{\prime} \mathrm{S}\right.$ e $53^{\circ} 20^{\prime} \mathrm{O}, 337 \mathrm{~m}$ de altitude). Floresta sobre Latossolo Vermelho-Amarelo, localizada no interflúvio da margem direita do Rio Pacuneiro.

Área 2 - Fazenda Boa Esperança, propriedade do Sr. Alfredo Zingler ( $13^{\circ} 10^{\prime} \mathrm{S}$ e $53^{\circ} 27^{\prime} \mathrm{O}, 357 \mathrm{~m}$ de altitude). Floresta sobre Latossolo Vermelho-Amarelo, localizada no interflúvio da margem esquerda do Rio Pacuneiro.

Área 3 - Fazenda Pontal, propriedade do Sr. Silvino Perotto $\left(13^{\circ} 06^{\prime} \mathrm{S}\right.$ e $53^{\circ} 23^{\prime}$ 'W, $314 \mathrm{~m}$ de altitude). Floresta ribeirinha com influência fluvial sazonal sobre Neossolo, localizada na margem esquerda do Rio Pacuneiro.

Cada local de coleta, além dos três acima citados, foi devidamente referenciado utilizando um GPS (Global System Position).

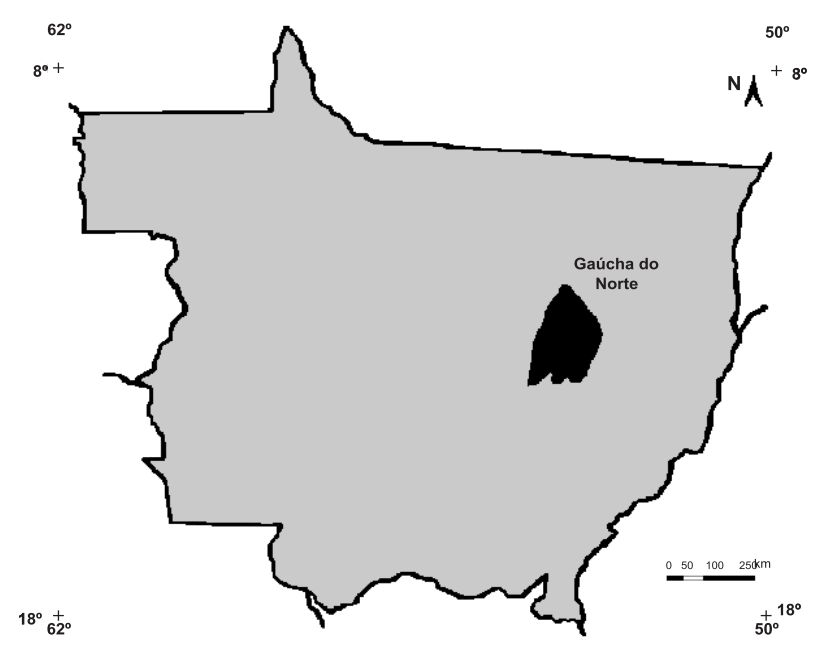

Figura 1 - Localização geográfica do município de Gaúcha do Norte no Estado de Mato Grosso. Fonte: SEPLAN/MT (1999). 


\section{ACTA AMAZONICA}

O levantamento florístico foi realizado em março de 1999 e bimestralmente a partir de agosto de 1999 até março de 2001, em excursões com duração média de 5 dias.

Durante as caminhadas de coleta, foram amostradas espécies em fase reprodutiva e predominantemente de porte arbustivo-arbóreo, devido à dificuldade de coleta de outras formas de vida (Ivanauskas et al., 2001).

A coleta do material botânico foi realizada com o auxílio de uma tesoura de poda alta, adaptada a três varas ajustáveis de alumínio, chegando a atingir até doze metros de altura. Asárvores de maior porte foram escaladas com esporas por profissional habilitado. No campo, foram anotados dados tais como: localização da espécie, hábito, altura (no caso de arbóreas, estimada usando-se como comparação a vara de coleta de tamanho conhecido), presença de látex, coloração e outros.

As espécies foram classificadas de acordo com o hábito, visando mostrar a distribuição da riqueza florística da área de estudo. Para isto foram consideradas as definições apresentadas em Raunkiaer (1934), Aubréville (1963), Dislich \& Mantovani (1998) e Kim (1996):

a) Árvore - Planta lenhosa que ramifica acima de $0,5 \mathrm{~m}$. Apresenta caule do tipo tronco.

b) Arbusto - Planta pequena, de base lenhosa, que ramifica abaixo de $0,5 \mathrm{~m}$ de altura.

c) Palmeira - Planta que apresenta caule do tipo estipe, pertencentes à família Arecaceae.

d) Erva - Planta herbácea (cujo caule não apresenta tecido lenhoso).

e) Liana - toda planta de hábito escandente de forma ampla, tanto herbácea quanto lenhosa.

f) Epífita - Foram incluídas nesta categoria apenas as epífitas vasculares verdadeiras, que são aquelas que utilizam outro vegetal apenas como suporte, e durante todo o seu ciclo de vida.

g) Hemiepífita - Planta que se apresenta na condição epifítica apenas durante uma parte do seu ciclo de vida.

h) Parasita - Planta que vive sobre outra, recorrendo ao sistema vascular do hospedeiro para suprir suas necessidades nutricionais.

O material coletado de cada indivíduo foi agrupado com fita crepe, numerado e transportado em sacos plásticos. No alojamento, o material foi organizado em prensas e seco em estufas, embalado em sacos plásticos e transportado para o Laboratório de Taxonomia da UNEMAT - NX, onde foi colocado em armário de aço, próprio para este fim, para posterior identificação.

Para a identificação foi utilizada bibliografia adequada, comparação com exsicatas existentes em herbários (ESA, UEC, IAC, SP, SPSF) ou ainda a consulta a especialistas. Os espécimes foram agrupados em famílias de acordo com o sistema de Cronquist (1988).

Após a identificação, o material foi incorporado ao herbário da Escola Superior de Agricultura "Luiz de
Queiroz"/USP (ESA), com duplicatas nos herbários da Universidade Estadual de Campinas (UEC), Universidade do Estado de Mato Grosso - Campus de Nova Xavantina (NX) e Universidade Estadual Paulista - campus de Rio Claro (HRCB), além de outros herbários quando houve envio de material a especialistas.

O esforço amostral foi verificado através da curva do coletor, na qual foi plotado o número acumulado de novas ocorrências em função dos meses de coleta, e pela proporção entre o número de novas ocorrências a cada mês e o total de material botânico coletado.

A fim de avaliar o atual estado de conhecimento da flora matogrossense, a listagem das espécies coletadas foi comparada com o banco de dados desenvolvido pela SEPLAN/MT (1999), visando identificar espécies ainda não registradas no Estado. O banco de dados da SEPLAN/MT contém os registros botânicos de 12.800 exemplares coletados no Mato Grosso e depositados no Herbário Central da Universidade Federal de Mato Grosso (UFMT), no Herbário do Museu Paraense Emílio Goeldi (MPEG) e no Herbário do Instituto Agronômico do Norte (IAN), devidamente sinonimizados. O mesmo banco de dados também inclui 856 espécies citadas nos pontos de coleta matogrossenses realizados pelo Projeto RADAMBRASIL $(1975,1978,1979,1980,1981 \mathrm{a}, 1981 \mathrm{~b}$, 1982a, 1982b, 1983). Além do banco de dados desenvolvido pela SEPLAN/MT, foi consultada a listagem publicada por Dubs (1998), que apresenta as exsicatas de plantas coletadas em Mato Grosso e depositadas em herbários no exterior.

\section{RESULTADOS E DISCUSSÃO}

O levantamento florístico das áreas florestais presentes em Gaúcha do Norte resultou em 437 coletas, distribuídas em 72 famílias, 168 gêneros e 268 espécies (Tabela 1). Houve repetição de coletas de uma mesma espécie quando esta foi encontrada ou em ambientes distintos ou em diferentes fases reprodutivas (com flores ou frutos).

Apesar do número de espécies ter aumentado linearmente a cada coleta realizada (Figura 2.A), foi necessário um esforço de amostragem cada vez maior (Figura 2.B) para manter esta função, pois a proporção de novas ocorrências tendeu a diminuir a cada excursão de campo.

O número de coletas realizadas a cada bimestre também não foi constante, apesar da freqüência regular ao campo, como pode ser constatado no pico de rendimento de coletas em dezembro (Figura 2.B): neste período houve maior disponibilidade de espécies com flores e/ou frutos e, consequentemente, maior coleta de novas ocorrências. Portanto, o esforço de coleta também está relacionado com a fenologia das espécies. No caso da área de estudo, os eventos reprodutivos parecem concentrar-se no final da estação seca e início da estação chuvosa (Figura 3). 


\section{ACTA \\ AMAZONICA \\ COMPOSIÇÃO FLORÍSTICA DE TRECHOS FLORESTAIS \\ NA BORDA SUL-AMAZÔNICA}

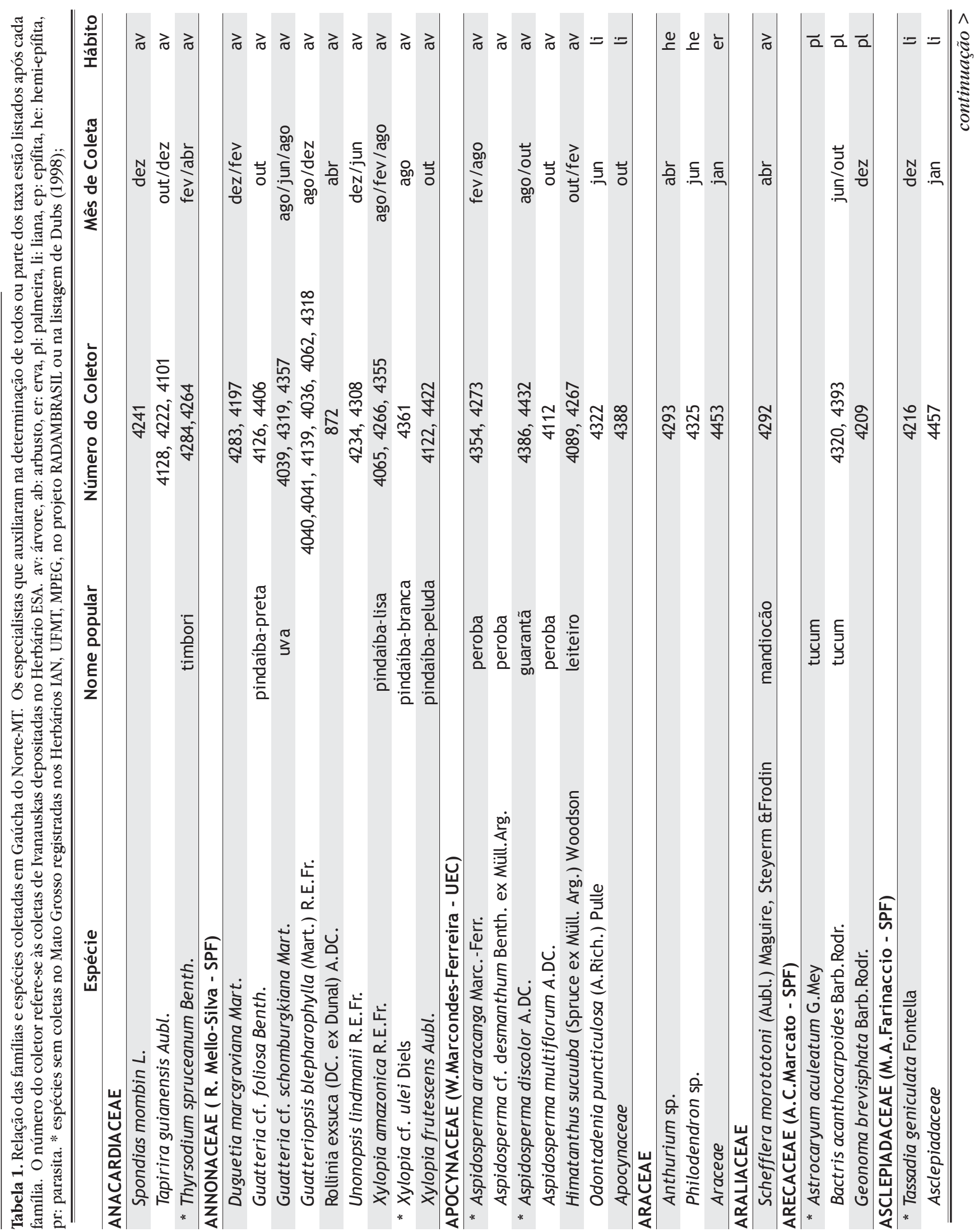




\section{\begin{tabular}{l|l} 
ACTA & COMPOSIÇÃO FLORÍSTICA DE TRECHOS FLORESTAIS
\end{tabular} \\ AMAZONICA NA BORDA SUL-AMAZÔNICA}

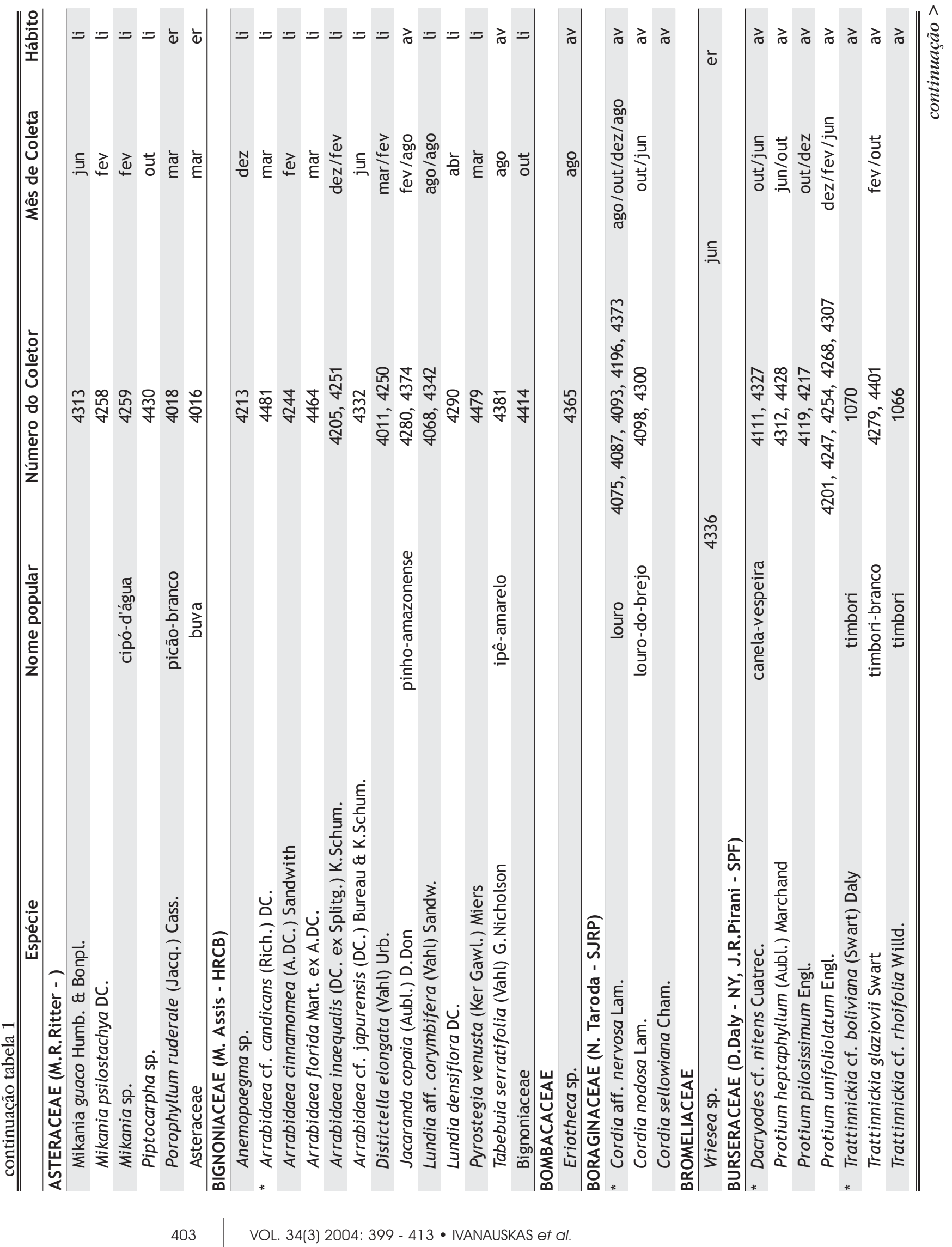




\section{ACTA \\ AMAZONICA \\ COMPOSIÇÃO FLORÍSTICA DE TRECHOS FLORESTAIS \\ NA BORDA SUL-AMAZÔNICA}

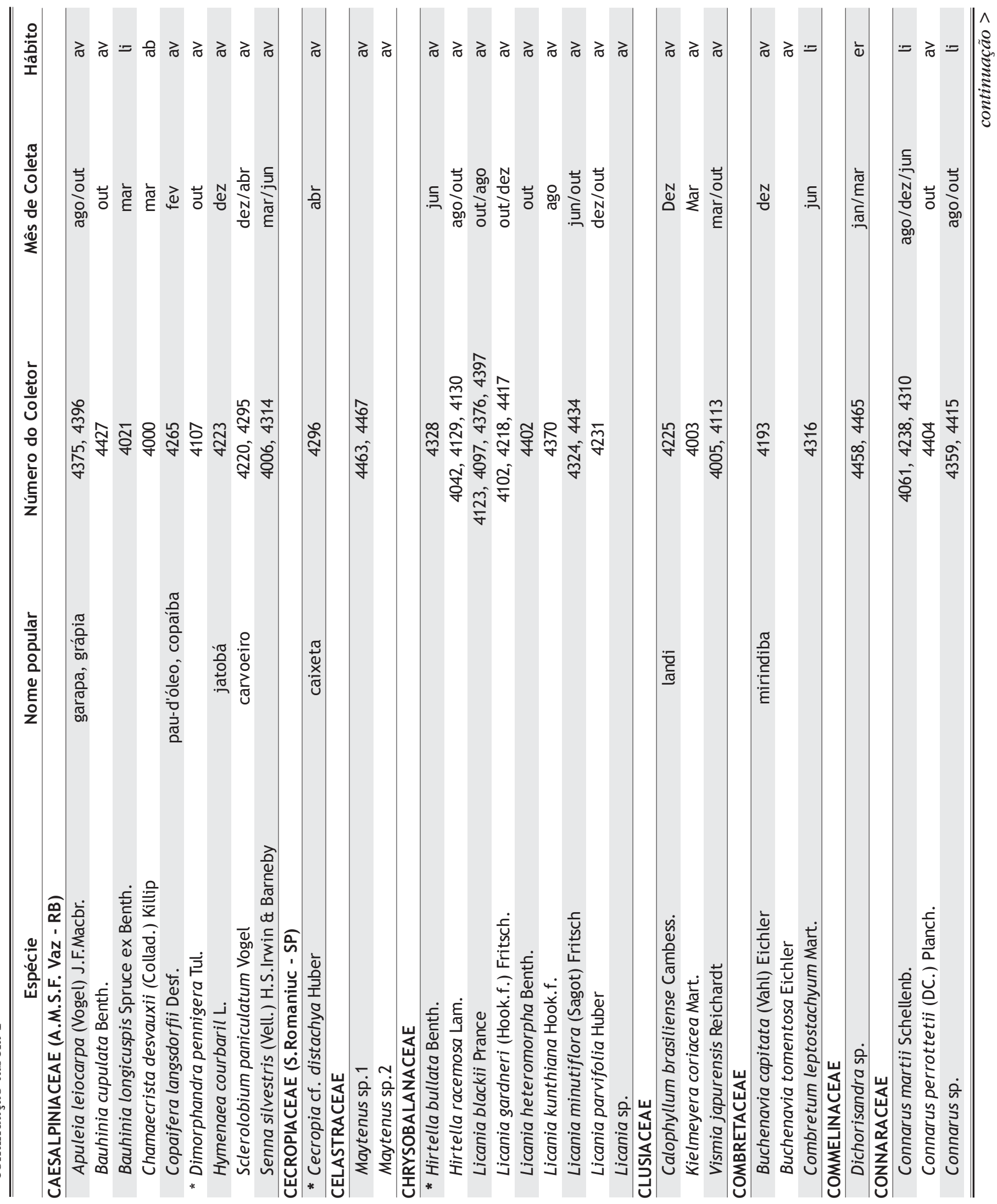




\section{ACTA \\ AMAZONICA \\ COMPOSIÇÃO FLORÍSTICA DE TRECHOS FLORESTAIS \\ NA BORDA SUL-AMAZÔNICA}

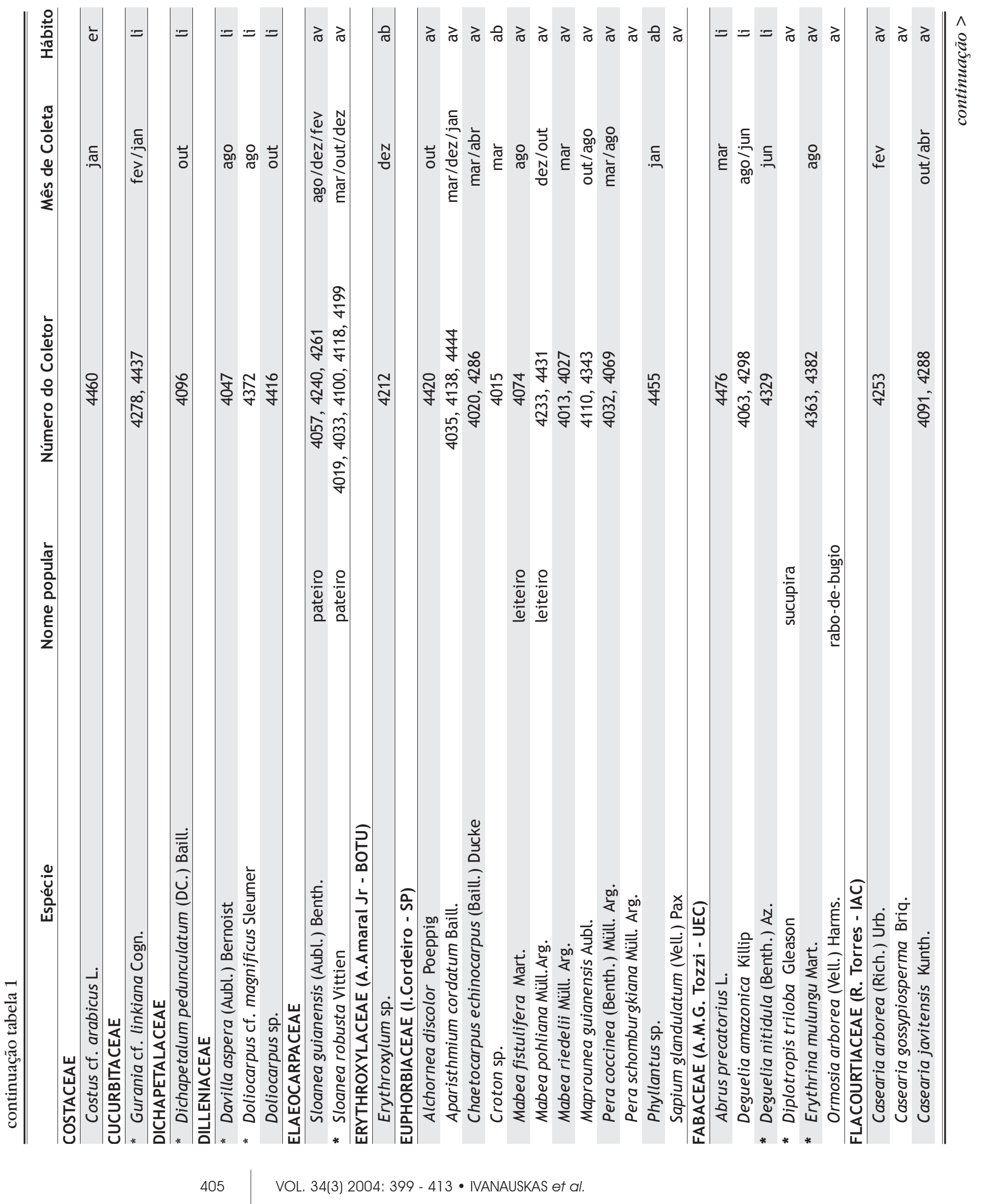




\section{ACTA \\ AMAZONICA \\ COMPOSIÇÃO FLORÍSTICA DE TRECHOS FLORESTAIS \\ NA BORDA SUL-AMAZÔNICA}

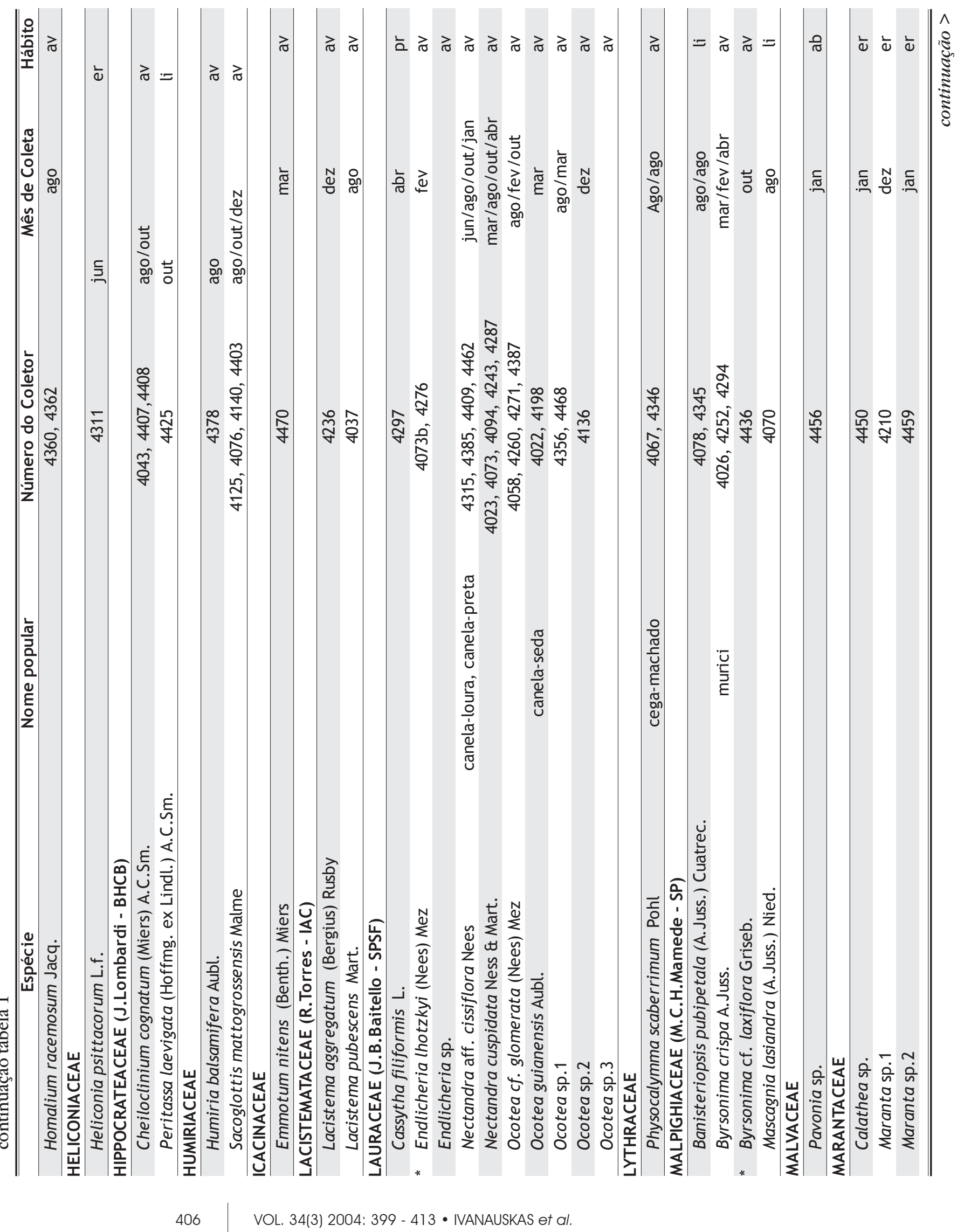




\section{ACTA \\ AMAZONICA \\ COMPOSIÇÃO FLORÍSTICA DE TRECHOS FLORESTAIS \\ NA BORDA SUL-AMAZÔNICA}

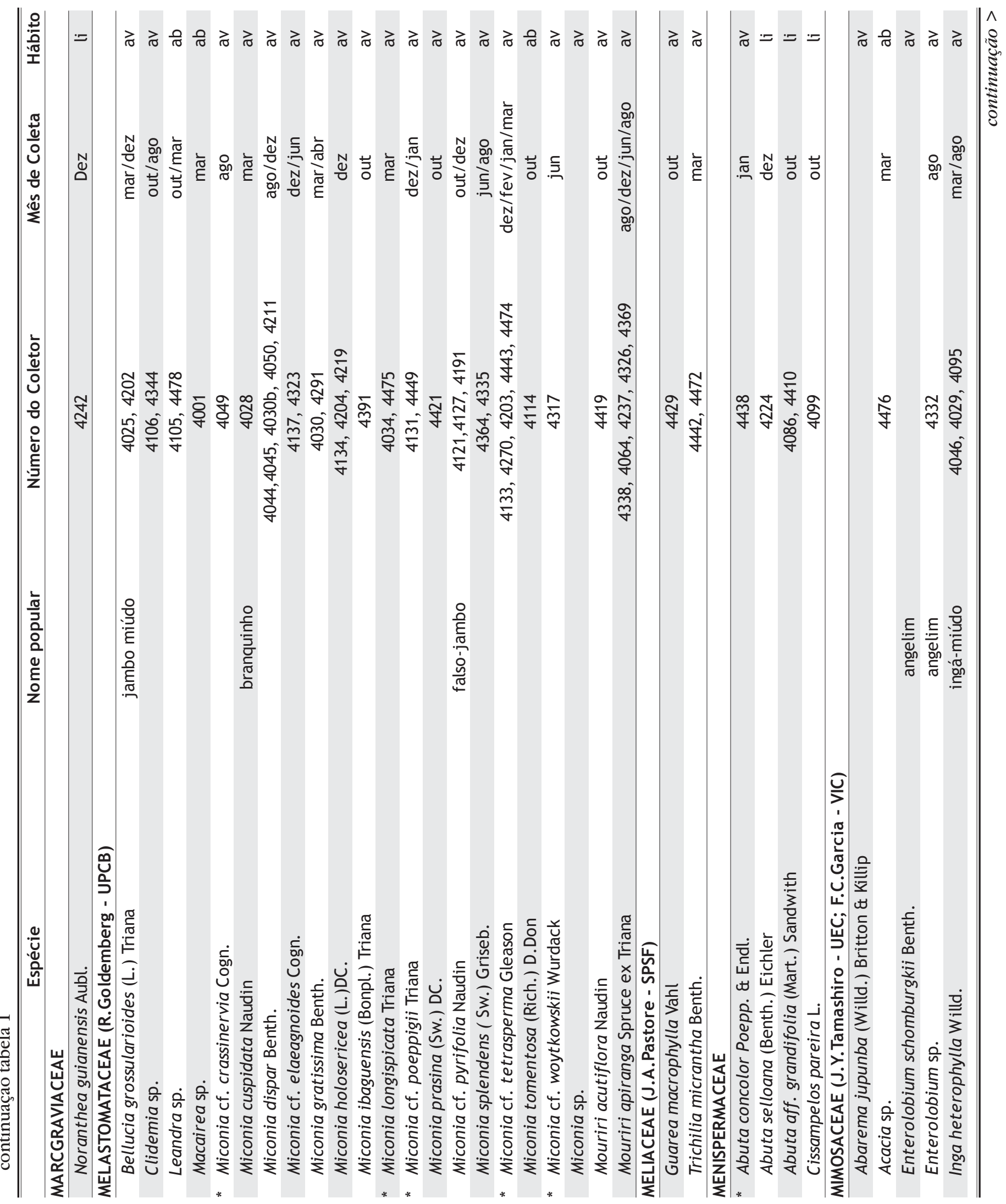




\section{ACTA \\ AMAZONICA \\ COMPOSIÇÃO FLORÍSTICA DE TRECHOS FLORESTAIS \\ NA BORDA SUL-AMAZÔNICA}

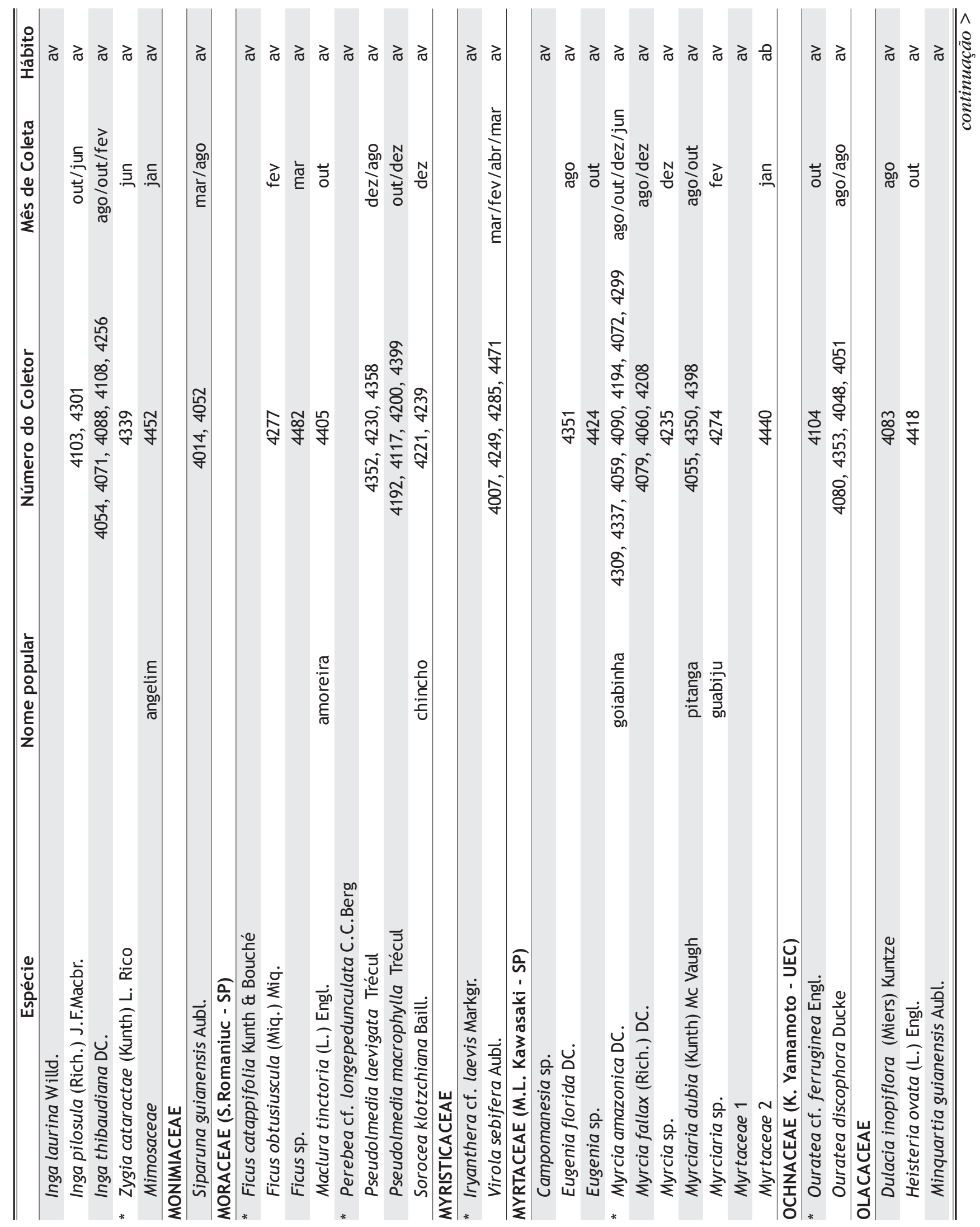




\section{ACTA \\ AMAZONICA

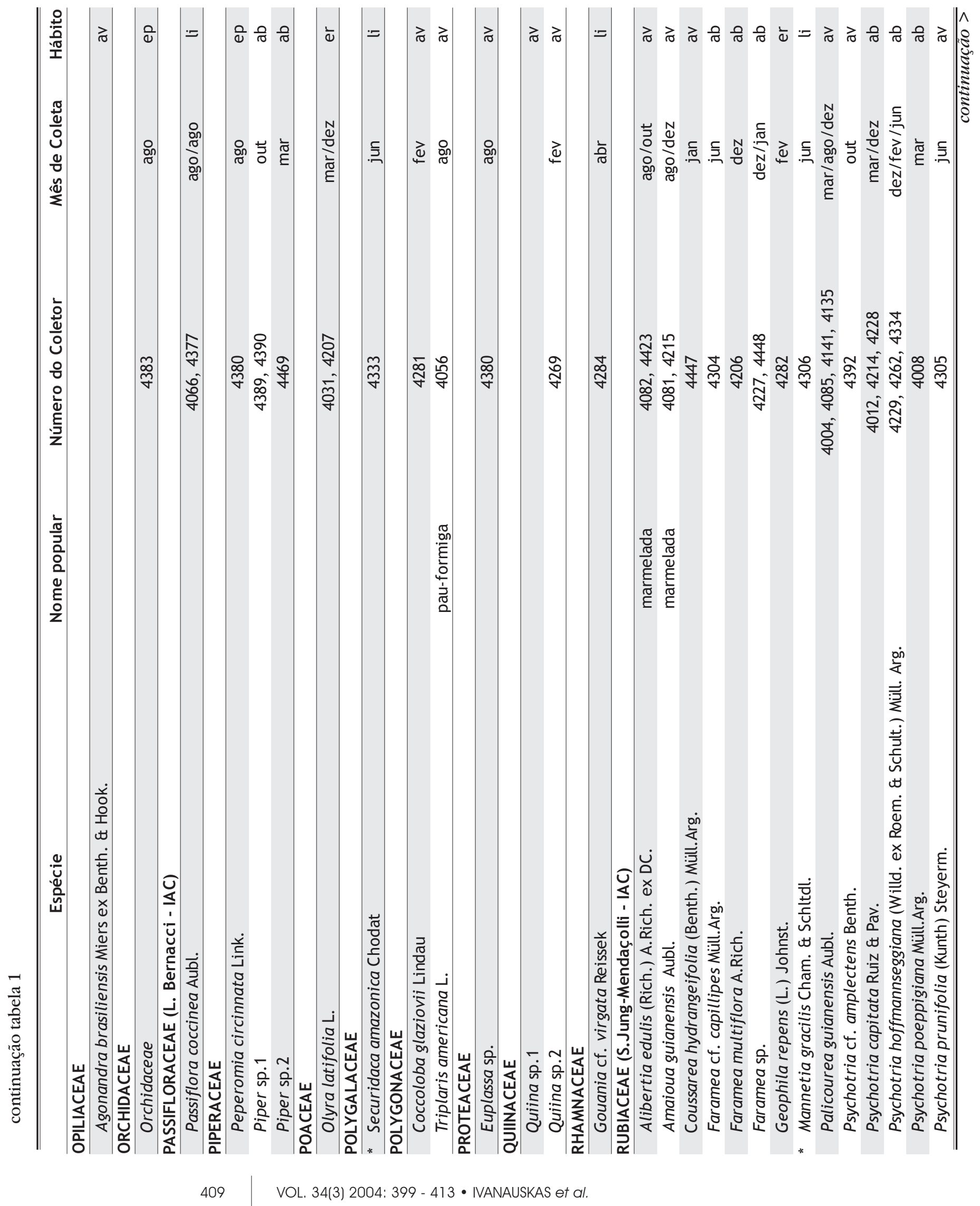




\section{ACTA \\ AMAZONICA \\ COMPOSIÇÃO FLORÍSTICA DE TRECHOS FLORESTAIS \\ NA BORDA SUL-AMAZÔNICA}

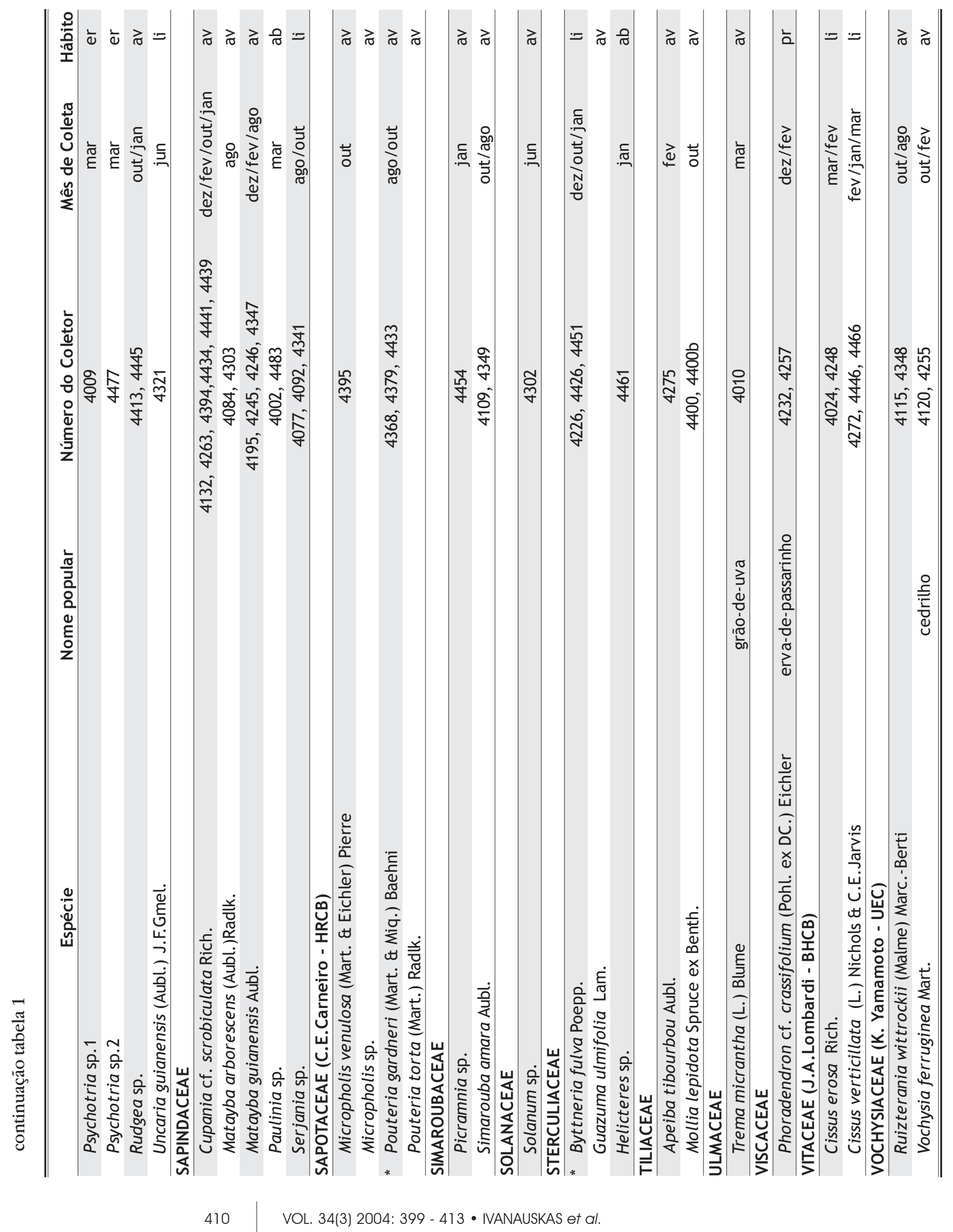




\section{ACTA AMAZONICA}
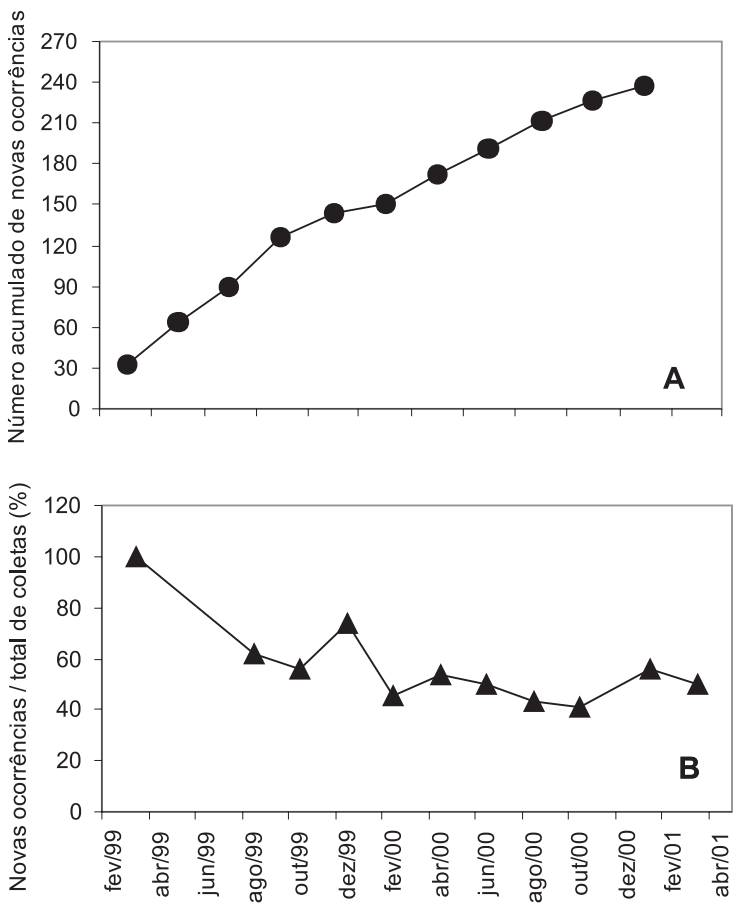

Figura 2. Número acumulado de novas ocorrências (A) e a proporção entre as novas ocorrências e o total de material coletado (B) de acordo com o mês, em florestas nativas em Gaúcha do Norte-MT.
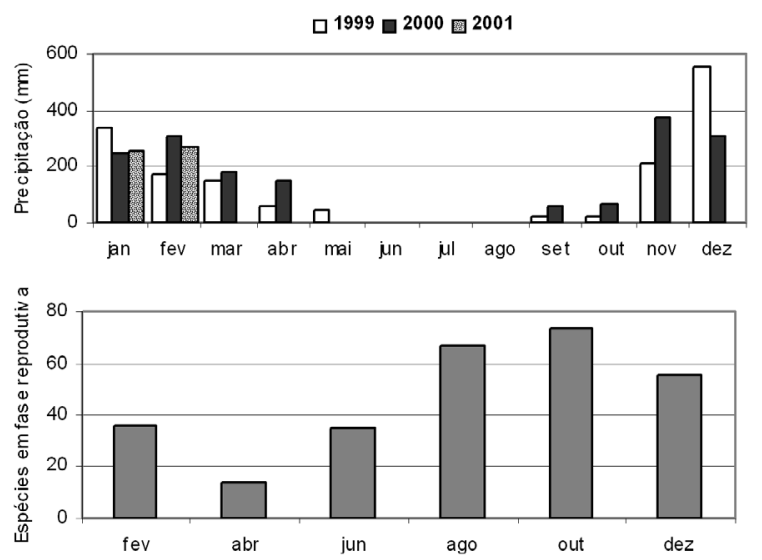

Figura 3. Precipitação e número de espécies em fase reprodutiva (flor e/ou fruto) no período de agosto/99 a março/01, em florestas nativas em Gaúcha do Norte-MT.

As famílias de maior riqueza florística são apresentadas na Figura 4. Nota-se o predomínio de famílias constituídas predominantemente por espécies de hábito arbóreo, com exceção de Bignoniaceae, predominante entre as lianas (Tabela 2). O predomínio de espécies arbóreas numa formação florestal é algo esperado, pois alguns estudos já demonstraram que as espécies desta forma de vida são as responsáveis por cerca de

50\% da riqueza encontrada na Floresta Atlântica (Lima \& Guedes-Bruni, 1994; Ivanauskas et al., 2000). Em Gaúcha do Norte, as espécies arbóreas representaram $66 \%$ do total de espécies amostradas, as lianas somaram $18 \%$ e as demais formas de vida assumiram valores inferiores a $8 \%$ (Tabela 2).

As espécies herbáceas e arbustivas restringiram-se às áreas de borda, às margens de cursos d'água e ao interior de clareiras, estando praticamente ausentes sob o dossel das áreas florestais, o que explica o baixo percentual encontrado. Já o destaque de lianas na comunidade deve ser ainda maior do que a constatado neste estudo, considerando-se que as lianas, epífitas e hemiepífitas estão subamostradas, pois há grande dificuldade de coleta e visualização destas formas de vida em áreas com dossel em torno de $20 \mathrm{~m}$.

Com relação à flora epifítica, pode-se afirmar que, apesar da subamostragem, há menor riqueza e densidade de espécies epífitas em Gaúcha do Norte do que em outras localidades amazônicas, as quais apresentam mais de 300 espécies registradas, considerando-se somente a família Orchidaceae (Silva et al., 1995). A baixa riqueza epifítica na área de estudo pode estar relacionada à fatores climáticos, pois Gaúcha do Norte encontra-se sob um clima mais seco do que grande parte da Amazônia, com precipitações anuais em torno de $1500 \mathrm{~mm}$ e períodos de seca de 3-4 meses. A influência da baixa umidade relativa do ar pôde ser constatada principalmente pela baixa densidade de espécies destas formas de vida nas áreas de interflúvio, e pela sua concentração em áreas próximas à cursos d'água. Esta concentração em áreas inundáveis também contribuiu para a subamostragem, pois o acesso ao interior das florestas só é possível no período seco, que por sua vez não é aquele em que se concentram os picos reprodutivos.

Outra dificuldade encontrada na execução do levantamento florístico foi a identificação das espécies. A flora amazônica é rica em famílias complexas taxonomicamente, como é o caso de Annonaceae, Burseraceae, Rubiaceae e Chrysobalanaceae, e há carência de taxonomistas especializados na flora da região.

Se a identificação do material coletado com flores e/ou frutos já é complicada, torna-se praticamente impossível a identificação de materiais vegetativos. Neste estudo, apesar da visita regular ao campo durante o período de dois anos, 29 espécies não foram observadas com flores e/ou frutos. Nas áreas de interflúvio, estas espécies não puderam ser coletadas por possuírem estratégias de reprodução com períodos de floração e frutificação muito breves (inferiores a um mês) ou supra anuais (acima de dois anos), ou ainda por tratarem-se de indivíduos jovens cujos parentais ou encontram-se fora da área de amostragem ou que não foram localizados devido à baixa freqüência. Já na floresta ribeirinha, a coleta de material reprodutivo foi prejudicada pela dificuldade de acesso à área no período chuvoso.

Assim, mesmo este trabalho, que apresenta um dos melhores índices de identificação específica quando comparado com outros trabalhos realizados na borda sul amazônica, das 268 espécies apresentadas na Tabela 1, 50 espécies encontram-se em nível de gênero e 9 em nível de 


\section{ACTA AMAZONICA}

COMPOSIÇÃO FLORÍSTICA DE TRECHOS FLORESTAIS

NA BORDA SUL-AMAZÔNICA

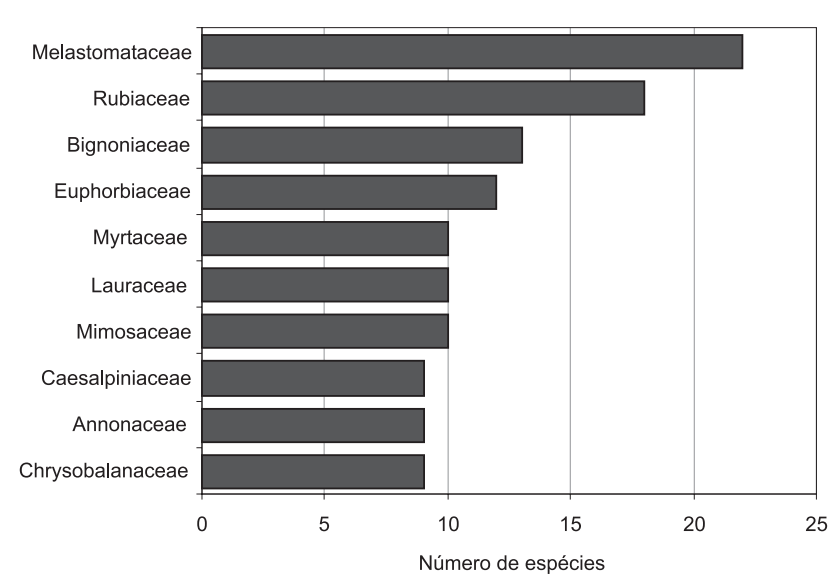

Figura 4. Famílias de maior riqueza em florestas nativas em Gaúcha do Norte-MT.

Tabela 2. Total de espécies agrupadas por hábito e as famílias de maior riqueza nessas formas de vida em Gaúcha do Norte-MT.

\begin{tabular}{|c|c|c|}
\hline Hábito & $\begin{array}{l}\text { Total de } \\
\text { Espécies }\end{array}$ & $\begin{array}{c}\text { Famílias de } \\
\text { maior riqueza }\end{array}$ \\
\hline Árvores & 178 & $\begin{array}{c}\text { Melastomataceae - 9\% } \\
\text { Euphorbiaceae - 6\% }\end{array}$ \\
\hline Lianas & 47 & $\begin{array}{c}\text { Bignoniaceae - 23\% } \\
\text { Asteraceae - 9\% }\end{array}$ \\
\hline Arbustos & 20 & $\begin{array}{c}\text { Rubiaceae - } 30 \% \\
\text { Melastomataceae - 15\% }\end{array}$ \\
\hline Ervas & 14 & $\begin{array}{c}\text { Rubiaceae - 21\% } \\
\text { Marantaceae - } 21 \%\end{array}$ \\
\hline Palmeiras & 3 & Arecaceae - 100\% \\
\hline Epífitas & 2 & $\begin{array}{c}\text { Orchidaceae - 50\% } \\
\text { Piperaceae - 50\% }\end{array}$ \\
\hline Hemiepífitas & 2 & Araceae - 100\% \\
\hline Parasitas & 2 & $\begin{array}{l}\text { Lauraceae - 50\% } \\
\text { Viscaceae - 50\% }\end{array}$ \\
\hline
\end{tabular}

família. Já 33 espécies precisam ser confirmadas por especialistas, pois somente a descrição, ou o material comparado em herbário, não foram suficientes para uma identificação segura.

Comparando-se as espécies coletadas em Gaúcha do Norte com os registros do banco de dados da SEPLAN/MT (1999), constatou-se que 39 espécies ainda não haviam sido depositadas em herbários com coleções representativas da flora matogrossense (Tabela 1). Este número tende a aumentar, quando o número de espécies indeterminadas for reduzido. A ausência destas espécies em herbários ressalta ainda mais a carência de coletas e o conhecimento precário da flora destas áreas de transição.

\section{AGRADECIMENTOS}

À Fundação de Amparo à Pesquisa do Estado de Mato Grosso (FAPEMAT), pelo Auxílio à Pesquisa. À Universidade do Estado de Mato Grosso (UNEMAT), pela bolsa de iniciação científica concedida aos alunos Rodney Haulien Oliveira Viana e Geane Pereira de Freitas.

\section{BIBLIOGRAFIA CITADA}

Ackerly, D.D.; Thomas, W.W.; Ferreira, C.A.C.; Pirani, J.R. 1989. The Forest-Cerrado transition zone in southern Amazonia: Results of the 1985 Projeto Flora Amazônica Expedition to Mato Grosso. Brittonia, 4 (12): 113-128.

Aubréville, A. 1963. Classification des formes biologiques des plantes vasculaires in milieu tropicale. Adansonia, (3):221-226.

Cronquist, A. 1988.The evolution and classification of flowering plants. The New York Botanical Garden, New York, USA. 555p.

Dislich, R.; Mantovani, W. 1998. A flora de epífítas vasculares da reserva da Cidade Universitária "Armando Salles de Oliveira" (São Paulo, Brasil). Bolm Bot. Univ. São Paulo, 17:61-83.

Dubs, B. 1998. Prodomus florae matogrossensis. Betrona-Verlag, Küsnacht.

Ferreira, L.V.; Sá, R.L.; Buschbacher, R.; Batmanian; G., Silva, J.M.C.; Arruda, M.B.; Moretti, E.; Sá, L.F.S.N.; Falcomer, J.; Bampi, M.I. 1999. Identificação de áreas prioritárias para a conservação da biodiversidade através da representatividade das unidades de conservação e tipos de vegetação nas ecorregióes da Amazônia brasileira. In: Avaliação e identificação de ações prioritárias para a conservação, utilização sustentável e repartição dos benefícios da biodiversidade da Amazônia brasileira: Programa Nacional da Diversidade Biológica. Seminário de Consulta, Macapá. Disponível na Internet via WWW. URL: http:/ /www.isa.org.br.

Flint, M. 1991. Biological Diversity and developing countries. Issue and options. Overseas Development Administration, London, England.

Ivanauskas, N.M.; Monteiro, R.; Rodrigues, R.R. 2001. Levantamento florístico de um trecho de Floresta Atlântica em Pariquera-Açu, SP. Naturalia, 26:97-129.

Kim, A.C. 1996. Lianas da mata atlântica do Estado de São Paulo. Dissertação de Mestrado, Universidade Estadual de Campinas, Campinas. 211p.

Köppen, W.P. 1948. Climatologia. Fondo de Cultura Economica, Mexico. $478 \mathrm{p}$.

Lima, M.P.M.; Guedes-Bruni, R.R. (Org.) 1994. Reserva Ecológica de Macaé de Cima, Nova Friburgo-RJ: aspectosflorísticos das espécies vasculares. Vol.1. Jardim Botânico, Rio de Janeiro, Brasil. 346p.

Peixoto, A.L.; Barbosa, M.R. 1998. Os Herbários Brasileiros e a Flora Nacional: Desafios para o Século 21. 24p. In Sistema de Informação sobre Biodiversidade / Biotecnologia para o Desenvolvimento Sustentável (OEA \& BDT). Disponível na Internet via WWW. URL: http://www.bdt.org.br/bdt/ oeaproj/herb.htm 


\section{ACTA AMAZONICA}

COMPOSIÇÃO FLORÍSTICA DE TRECHOS FLORESTAIS NA BORDA SUL-AMAZÔNICA
Projeto RADAMBRASIL, 1975. Levantamento de Recursos Naturais, Folha Tapajós (SB-21). BRASIL - Departamento Nacional de Produção Mineral, Rio de Janeiro, Brasil. 409p.

Projeto RADAMBRASIL, 1978. Levantamento de Recursos Naturais, Folha Porto Velho (SC-20). BRASIL - Departamento Nacional de Produção Mineral, Rio de Janeiro, Brasil. 663p.

Projeto RADAMBRASIL, 1979. Levantamento de Recursos Naturais, Folha Guaporé (SD-20). BRASIL - Departamento Nacional de Produção Mineral, Rio de Janeiro, Brasil. 364p.

Projeto RADAMBRASIL, 1980. Levantamento de Recursos Naturais, Folha Juruena (SC-21). BRASIL - Departamento Nacional de Produção Mineral, Rio de Janeiro, Brasil. 460p.

Projeto RADAMBRASIL, 1981a. Levantamento de Recursos Naturais, Folba Tocantins (SC-22). BRASIL - Departamento Nacional de Produção Mineral, Rio de Janeiro, Brasil. 520p.

Projeto RADAMBRASIL, 1981b. Levantamento de Recursos Naturais, Folba Goiás (SD-22). BRASIL - Departamento Nacional de Produção Mineral, Rio de Janeiro, Brasil. 636p.

Projeto RADAMBRASIL, 1982a. Levantamento de Recursos Naturais, Folba Corumbá (SE-21). BRASIL - Departamento Nacional de Produção Mineral, Rio de Janeiro, Brasil. 448p.

Projeto RADAMBRASIL, 1982b. Levantamento de Recursos Naturais, Folba Cuiabá (SD-21). BRASIL - Departamento Nacional de Produção Mineral, Rio de Janeiro, Brasil. 540p.
Projeto RADAMBRASIL, 1983. Levantamento de Recursos Naturais, Folha Goiânia (SE-22). BRASIL - Departamento Nacional de Produção Mineral, Rio de Janeiro, Brasil. 764p.

Raunkiaer, C. 1934. The Life Forms of Plants and Statistical Plant Geography. Claredon, Oxford, USA. 632p.

Sampaio, A.J. 1916. A flora de Mato Grosso. Arq. Mus. Nac. Rio de Janeiro, 19:1-25.

SEPLAN/MT. 1999. Dados secundários do DSEE/MT: Zoneamento -Divulga. CD-Rom. Versão 1.01.

Silva, M.F.F.; Silva, J.B.F.; Rocha, A.E.S.; Oliveira, F.P.M.; Gonçalves, L.S.B.; Silva, M.F.; Queiroz, O.H.A. 1995. Inventário da família Orchidaceae na Amazônia brasileira. Acta bot. Brasilica, 9(1): 163-175.

\section{RECEBIDO EM 26/03/2003 \\ ACEITO EM 17/07/2004}

